Abstracta Iranica Abstranica

Revue bibliographique pour le domaine irano-aryen

Volume 42-43 | 2021

Comptes rendus des publications de 2019-2020

\title{
Samuel N. C. Lieu, Glen L. Thompson (eds.). The Church of the East in Central Asia and China
}

\section{Christelle Jullien}

\section{(2) OpenEdition}

1 Journals

\section{Édition électronique}

URL : https://journals.openedition.org/abstractairanica/54142

DOI : 10.4000/abstractairanica.54142

ISSN : 1961-960X

Éditeur :

CNRS (UMR 7528 Mondes iraniens et indiens), Éditions de l'IFRI

\section{Référence électronique}

Christelle Jullien, « Samuel N. C. Lieu, Glen L. Thompson (eds.). The Church of the East in Central Asia and China ", Abstracta Iranica [En ligne], Volume 42-43 | 2021, document 24, mis en ligne le 30 décembre 2021, consulté le 14 décembre 2022. URL : http://journals.openedition.org/ abstractairanica/54142 ; DOI : https://doi.org/10.4000/abstractairanica.54142

Ce document a été généré automatiquement le 14 décembre 2022.

Tous droits réservés 


\title{
Samuel N. C. Lieu, Glen L. Thompson (eds.). The Church of the East in Central Asia and China
}

\author{
Christelle Jullien
}

\section{RÉFÉRENCE}

Samuel N. C. Lieu, Glen L. Thompson (eds.). The Church of the East in Central Asia and China. Turnhout: Brepols, 2020, 260 p., 25 ill. en couleur. ISBN: 978-2-503-58664-9.

(China and the Mediterranean World 1)

1 Cet ouvrage constitue le premier d'une nouvelle série chez Brepols, "China and the Mediterranean World" dont S. N. C. Lieu et G. Mikkelsen sont les "General Editors". Il est le fruit d'une rencontre internationale qui a réuni en 2015 à Hong Kong des spécialistes sur la question des dernières découvertes d'églises chrétiennes en Chine à l'ère Tang (618-907) ainsi qu'au cours des dernières périodes Song (960-1279) et Yuan (1279-1386). Les documents rassemblent ainsi des témoignages archéologiques et littéraires inédits. Ce livre collectif est formé de 11 contributions sur cette présence chrétienne et plus généralement sur l'histoire du christianisme en Asie centrale et dans la Chine pré-moderne, reflet de l'essor de ce domaine de recherche ces toutes dernières années.

2 La première partie est consacrée aux documents sur l'Église d'Orient en Asie centrale, et plus spécialement à ceux retrouvés à Turfan en sogdien, relevant des genres hagiographique (E. Hunter) et biblique (N. Sims-Williams). T. Hidemi étudie la lexicographie syriaque présente dans les documents chinois. Parmi les articles de la seconde partie, dévolue à la Chine Tang et Yuan, celui de C. Huaiyu s'intéresse au phénomène d'intertextualité entre bouddhistes, chrétiens et daoistes; $S$. Lieu réévalue à nouveaux frais la stèle de Xi' an comme document transculturel; G. Thompson approfondit les notions d'"étranger" et d'hérésie dans la réception de l'enseignement 
chrétien en Chine à cette époque; enfin D. Wilmshurst s'intéresse aux controverses interreligieuses dans la Chine Yuan. La dernière rubrique a trait à l'art et à l'iconographie de l'Église d'Orient : N. Ruji présente l'expansion des communautés syroorientales en Chine à la lumière de découvertes archéologiques et épigraphiques (en syriaque particulièrement) récentes; en complément, $P$. Taveirne propose un status quaestionis sur le corpus des croix nestoriennes en bronze; K. Parry ouvre les discussions avec une réflexion sur les représentations textuelles et artistiques de l'Église syro-orientale à la lumière de pratiques contemporaines. D'utiles indices viennent clore ce volume qui marque une importante étape dans l'histoire de la recherche en offrant une vision renouvelée de notre perception du christianisme en Chine, à l'appui de documents uniques ou revisités.

Table des matières

Première partie : L'Église d'Orient en Asie centrale

E. Hunter, "The Christian Library from Turfan: commemorating the saints in MIK III/ $45 "$ (p. 1-12);

N. Sims-Williams, "Sogdian Biblical Manuscripts from the Turfan Oasis" (p. 13-21) ;

T. Hidemi, "Representation of the Syriac language in Jingjiao documents" (p. 23-92) ;

Deuxième partie : L'Église d'Orient dans la Chine des Tang et des Yuan

H. Chen, "Shared Issues in a Shared Textual Community: Buddhist, Christian, and Daoist Texts in Tang Chin" (p. 93-109);

M. Deeg, "Messiah Rediscovered: Some Philological Notes on the So-called "Jesus the Messiah Sutra" " (p. 111-119) ;

S. N. C. Lieu, “From Rome (Daqin 大秦) To China (Zhongguo 中國): The Xi'an 西安 (Nestorian) Monument As A Bilingual And Transcultural Document (Keynote Address)" (p. 121-141) ;

G. L. Thompson, "Strange Teaching from a Strange Land: Foreignness, Heresy, and Our Understanding of the Jingjiao and Yelikewenjiao" (p. 143-163) ;

D. Wilmshurst, "Interfaith Conflict in Yuan China" (p. 164-175).

Troisième partie : L'art et l'iconographie de l'Église d'Orient

N. Ruji, "History Is a Mirror: On the Spread of Nestorianism in China from the Newly Discovered Bronze Mirror with Cross-lotus and Syriac Inscriptions" (p. 177-188) ;

K. Parry, "Images in the Church of the East: The Textual and Art Historical Evidence in the Light of Contemporary Practice" (p. 189-212);

7 P. Taveirne, "The Study of the Ordos "Nestorian Bronze Crosses": Status Quaestionis" (p. 213-233).

8 Addenda au chap. 3, Index. 


\section{AUTEURS}

CHRISTELLE JULLIEN

CNRS, CeRMI, Paris 